\title{
Could boron-containing compounds (BCCs) be effective against SARS-CoV-2 as anti-viral agent?
}

\author{
Cetiner $\mathrm{E}^{1}$, Sayin $\mathrm{K}^{1}$, Tuzun $\mathrm{B}^{1}$, Ataseven $\mathrm{H}^{2}$ \\ Faculty of Science, Department of Chemistry, Sivas Cumhuriyet University, Sivas, Turkey. \\ krysayin@gmail.com
}

\begin{abstract}
BACKGROUND: Seven dioxaborole compounds are investigated in this study. Structural and spectral characterizations are done at the M062X/6-31+G(d,p) level in water. Active sites of these compounds are determined by contour plots of frontier molecular orbital and molecular electrostatic potential (MEP) maps. Electrophilic and nucleophilic attack regions are determined. Since SARS-CoV-2 is a worldwide health problem, antiviral properties of studied boron-containing compounds are investigated by molecular docking calculations. In addition to these calculations, MM/PSBA calculations are performed. RESULTS AND CONCLUSION: It is found that the studied boron compounds can be good drug candidates against the main protease of SARS-CoV-2, while the best of them is 4,6-di-tert-butyl-2-(4-methoxyphenyl) benzo[d][1,3,2] dioxaborole (B2) (Tab. 3, Fig. 8, Ref. 23). Text in PDF www.elis.sk KEY WORDS: boronate ester, dioxaborole, in silico, SARS-CoV-2, MD calculations.
\end{abstract}

\section{Introduction}

Boroles are derived from cyclopentadienes which are five-membered heterocycles. A BR group replaces the $\mathrm{C}(\mathrm{R} 1 \mathrm{R} 2)$ group. The first borole compounds have been reported by Braye et al in 1961 (1, 2). After that, many improvements and declines ook place. In 2008, pentaphenylborole was characterized for the first time by Braunschweig and coworkers (3). Boron-containing compounds (BCCs) have broad application areas such as optic, biological, anticancer, antiviral, etc. It has been reported that medical drugs containing boron have toxicity. However, all studies investigating the toxicity of boron-containing medical drugs deal only with boric acid and phenylboronic acid (4). In the late 20th century, it was precisely reported that elemental boron and many BCCs have low toxicity for humans and animals. Researches on this subject have shown that the toxicity is not directly caused by boron (4). Many researches and preclinic tests with this aim have been still performed (4). In this study, the structural and electronic properties of dioxaborole compounds, and especially their antiviral effects against SARS-CoV-2 are analyzed by means of the in silico technique. Also, the computations of molecular-mechanics energies were combined with the

${ }^{1}$ Faculty of Science, Department of Chemistry, Sivas Cumhuriyet University, Sivas, Turkey, and ${ }^{2}$ Faculty of Medicine, Department of Gastroenterology, Sivas Cumhuriyet University, Sivas, Turkey

Address for correspondence: K. Sayin, Faculty of Science, Department of Chemistry, Sivas Cumhuriyet University, Sivas, Turkey

Acknowledgements: The numerical calculations reported in this paper were fully/partially performed at TUBITAK ULAKBIM, High Performance and Grid Computing Center (TRUBA resources). This work is supported by the Scientific Research Project Fund of Sivas Cumhuriyet University under the project number RGD-020.

\begin{tabular}{lllllll}
\hline & $\mathrm{ID}$ & $\mathrm{R}_{1}$ & $\mathrm{R}_{2}$ & $\mathrm{R}_{3}$ & $\mathrm{R}_{4}$ & $\mathrm{R}_{5}$ \\
\hline & $\mathrm{B} 1$ & $-\mathrm{H}$ & $-\mathrm{H}$ & $-\mathrm{H}$ & $-\mathrm{H}$ & $-\mathrm{H}$ \\
& $\mathrm{B} 2$ & $-\mathrm{H}$ & $-\mathrm{H}$ & $-\mathrm{OCH}_{3}$ & $-\mathrm{H}$ & $-\mathrm{H}$ \\
& $\mathrm{B} 3$ & $-\mathrm{H}$ & $-\mathrm{H}$ & $-\mathrm{CF}_{3}$ & $-\mathrm{H}$ & $-\mathrm{H}$ \\
& $\mathrm{B} 5$ & $-\mathrm{Cl}$ & $-\mathrm{Cl}$ & $-\mathrm{Cl}$ & $-\mathrm{Cl}$ & $-\mathrm{Cl}$ \\
& $\mathrm{B} 7$ & $-\mathrm{H}$ & $-\mathrm{H}$ & $-\mathrm{CN}$ & $-\mathrm{H}$ & $-\mathrm{H}$ \\
\hline
\end{tabular}

Fig. 1. Studied dioxaborole compounds.

Poisson-Boltzmann surface area (MM/PBSA) analysis. In Scheme 1, the studied dioxaborole compounds are presented (Fig. 1).

Some of these compounds, namely B1-B4, were synthesized by Bentley and Caputo in 2019 (5). All compounds are optimized at the M062X/6-31+G(d,p) level in water. Their structural and electronic properties are analyzed in detail. Due to the articles showing that BCCs may be useful in the treatment of COVID19 (6), the antiviral effect of these compounds is also examined by molecular docking analysis. There are three significant structures in SARS-CoV-2, RNA-dependent RNA polymerase (RdRp), main protease and spike protein. These proteins are different from each other, and each has its own characteristics. These proteins are searched in the protein data bank (PDB) web tool. The 6LZG (7), 6YYT (8) and 6WTT (9) structures are selected for the spike protein, RdRp and main protease, respectively. The molecular docking calculations are performed at extra precision, and three poses for each receptor-drug interaction are taken into consideration, if 

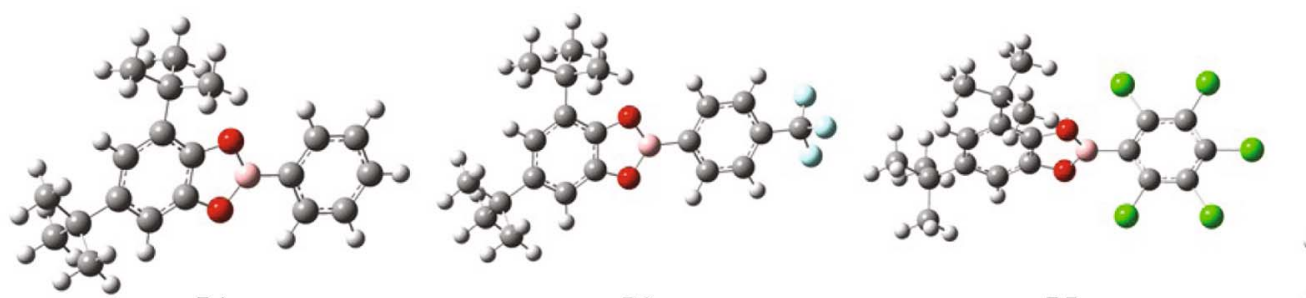

B1

B3

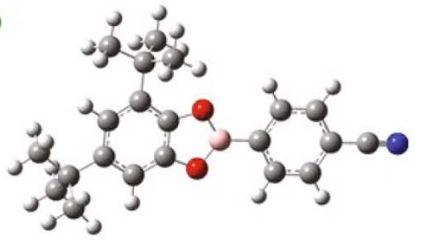

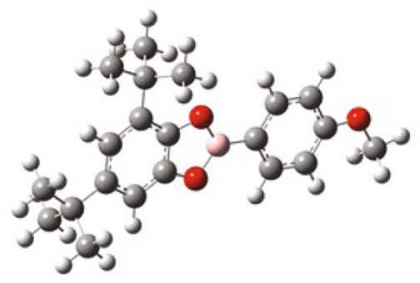

B2

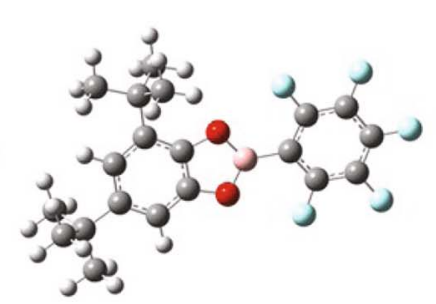

B4
B5

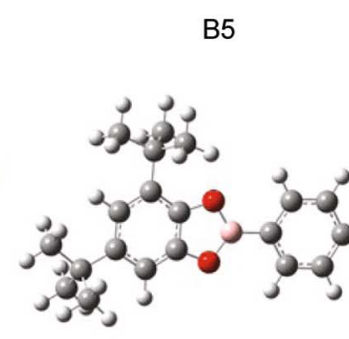

B6

Fig. 2. The optimized structure of studied dioxaborole compounds.

existent. Finally, the MM/PBSA calculations are performed. Especially, energy values in receptor-protein interactions are examined at every 5-ns interval. Finally, it is decided whether the chemical structures of drug candidates for each target protein are mainly different from each other.

\section{Method}

Computational analyses of dioxaborole compounds were performed. Four types of software, Gaussian, Maestro, Visual Molecular Dynamics and Nanoscale Molecular Dynamics were used in this study (10-17). Initially, the selected compounds are optimized by the M06-2X method at the $6-31+G(d, p)$ level in water. In order to take into consideration the solute-solvent interactions, the polarizable continuum model (PCM) was used, namely its integral equation formalism variant (IEF-PCM). Their structural and electronic properties were analyzed in detail, especially, the molecular orbitals. Particularly, the highest occupied molecular orbital (HOMO and the lowest unoccupied molecular orbital (LUMO) are investigated, and molecular electrostatic potential (MEP) maps are examined in detail. The analyses mentioned above were done using the Gaussian program.

The in silico molecular docking calculations were done using the Maestro program. In this step, LigPrep, Protein Preparation, SiteMap, Receptor Grid Generation, Ligand Docking and Ligand Interaction modules are used. Studied compounds were re-minimized with the OPLS3e method at $\mathrm{pH}=7$ \pm 2 . The 6LZG, 6YYT and 6WTT structures

${ }^{\mathrm{b}}$ in $\mathrm{kcal} / \mathrm{mol}$ were prepared, and site maps were calculated. Receptor-binding domains (RBDs) were defined using the Receptor Grid Generation module. Molecular docking calculations between studied dioxaborole and target proteins were performed.

In the last step, the energies computed by molecular mechanics were combined with the Poisson-Boltzmann or generalized Born surface area (MM/PBSA) methods for each ligand-protein interaction by NAMD and VMD software. Gibbs binding energy, van der Walls energy, kinetic energy and potential energy were calculated for each 5-ns interval.

Tab. 1. Structural parameters of B1-B7.

\begin{tabular}{lccccccc}
\hline Assignment & B1 & B2 & B3 & B4 & B5 & B6 & B7 \\
\hline Bond Length $(\AA)$ & & & & & & & \\
\hline B1-O1 & 1.389 & 1.391 & 1.385 & 1.380 & 1.378 & 1.386 & 1.385 \\
B1-O2 & 1.387 & 1.389 & 1.384 & 1.379 & 1.376 & 1.384 & 1.383 \\
O1-C1 & 1.377 & 1.377 & 1.378 & 1.380 & 1.381 & 1.378 & 1.378 \\
C3-C4 & 1.403 & 1.403 & 1.403 & 1.409 & 1.404 & 1.403 & 1.403 \\
C8-C9 & 1.393 & 1.394 & 1.393 & 1.387 & 1.397 & 1.395 & 1.390 \\
C10-R & 1.086 & 1.355 & 1.502 & 1.328 & 1.724 & 1.521 & 1.441 \\
\hline Bond angles (deg.) & & & & & & & \\
\hline O1-B1-C7 & 124.6 & 124.9 & 124.5 & 124.3 & 124.1 & 124.6 & 124.4 \\
O2-B1-C7 & 124.4 & 124.4 & 124.3 & 124.0 & 123.8 & 124.2 & 124.3 \\
O1-B1-O2 & 110.9 & 110.7 & 111.2 & 111.7 & 112.0 & 111.2 & 111.3 \\
O1-C1-C2 & 128.0 & 128.0 & 128.0 & 127.7 & 128.0 & 128.0 & 128.0 \\
C7-C8-C9 & 120.7 & 121.8 & 120.8 & 122.7 & 121.7 & 121.2 & 120.8 \\
C9-C10-R & 119.9 & 124.1 & 120.3 & 120.1 & 119.3 & 122.5 & 119.5 \\
\hline
\end{tabular}

Tab. 2. Molecular docking results.

\begin{tabular}{lcccccccc}
\hline Protein & Compounds & $\mathrm{DS}^{\mathrm{b}}$ & LE $^{\mathrm{b}}$ & LE-SA $^{\mathrm{b}}$ & $\mathrm{E}_{\text {Model }} \mathrm{b}^{\mathrm{b}}$ & $\mathrm{E}_{\mathrm{VDW}}{ }^{\mathrm{b}}$ & $\mathrm{E}_{\text {Coul }} \mathrm{b}^{\mathrm{b}}$ & $\mathrm{E}_{\text {Int }} \mathrm{b}^{\mathrm{b}}$ \\
\hline \multirow{2}{*}{ 6LZG } & $\mathrm{B} 1(1)$ & -3.170 & -0.138 & -0.392 & -28.865 & -25.475 & -1.598 & -27.073 \\
& $\mathrm{~B} 7(1)$ & -2.639 & -0.106 & -0.309 & -50.260 & -35.041 & -1.461 & -36.502 \\
& $\mathrm{~B} 7(2)$ & -2.631 & -0.105 & -0.308 & -46.469 & -35.013 & -1.449 & -36.463 \\
\hline \multirow{2}{*}{ 6WTT } & $\mathrm{B} 2(1)$ & -4.701 & -0.188 & -0.550 & -37.145 & -25.494 & -1.444 & -26.937 \\
& $\mathrm{~B} 2(2)$ & -4.227 & -0.169 & -0.494 & -37.360 & -30.936 & -1.011 & -31.948 \\
& $\mathrm{~B} 5(1)$ & -3.919 & -0.140 & -0.425 & -41.605 & -35.965 & -0.054 & -36.019 \\
\hline 6YYT & $\mathrm{B} 1(1)$ & -0.573 & -0.025 & -0.071 & 14.688 & -13.945 & -0.105 & -14.049 \\
\hline
\end{tabular}

${ }^{a}$ Number given in parenthesis is the pose number in molecular docking 


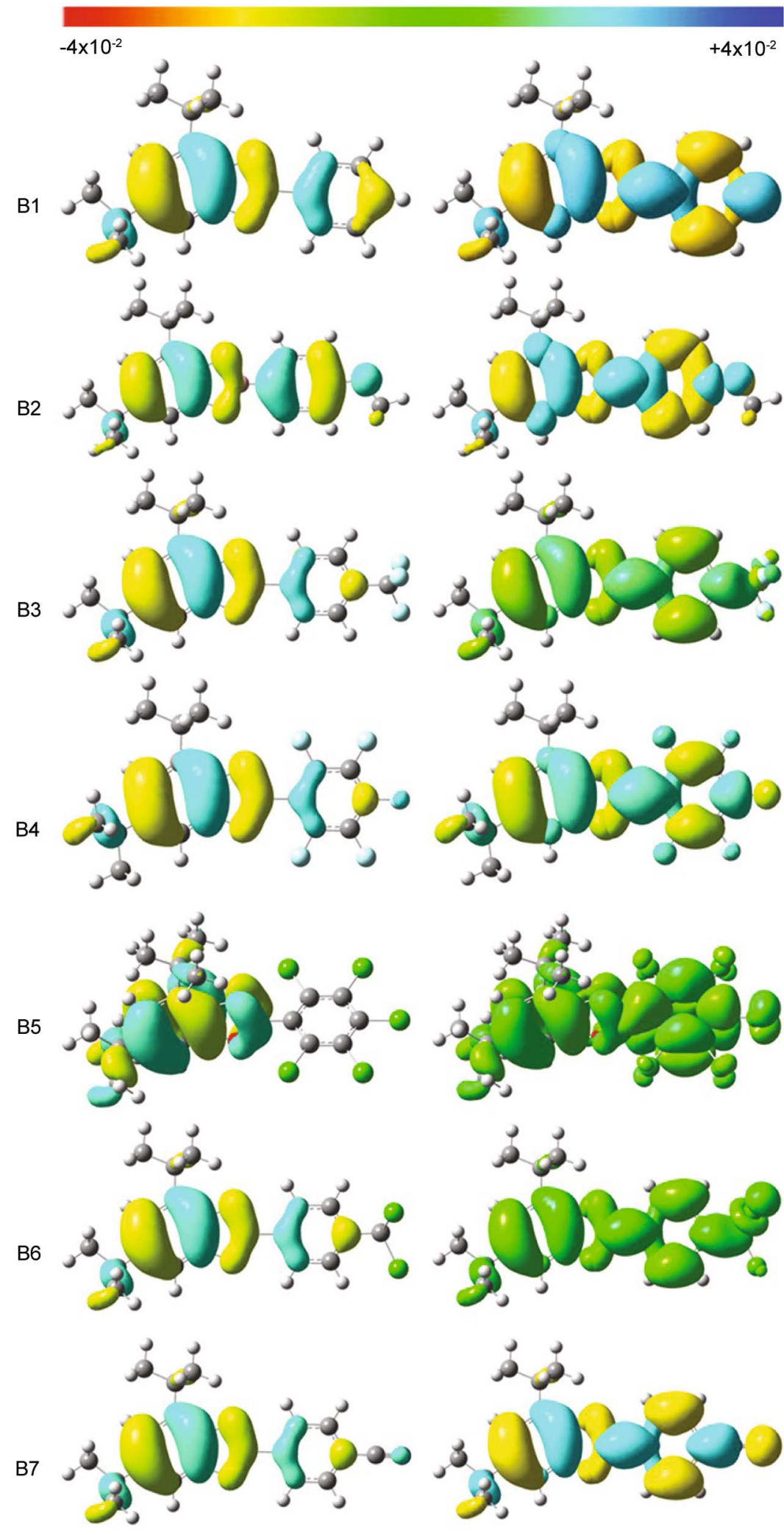

Fig. 3. The contour plots of studied compounds.

\section{Results and discussions}

Quantum chemical calculations

Studied dioxaborole compounds are optimized at the M06-2X/6-31+G(d,p) level in water, and optimized structures are presented in Figure 2. Additionally, selected structural parameters are given in Table 1.

According to Table 1, bond lengths of B-O are calculated to be nearly $1.39 \AA$, and this bond length has been reported to be about $1.38 \AA$ (18). O-C and C-C bond lengths are calculated to be nearly 1.37 and $1.40 \AA$, respectively. The carbon-carbon bond length in the benzene ring has been reported to be about $1.38 \AA(19,20)$. The whole structures are planar except for the compound B5. The contour plots of frontier molecular orbitals are calculated to determine the active regions of studied compounds. The related diagrams are presented in Figure 3.

According to Figure 2, $\pi$ electrons are mainly active for any interaction in both molecular orbitals. There are balloons in the environment of these electrons in benzene rings. Additionally, heteroatoms which are oxygen, fluorine, chlorine, and nitrogen seem to be inactive in HOMO diagrams while there are balloons in LUMO plots. On the other hand, these balloons have different colours. Each color has a different meaning relative to the electron density. The color scale is presented with the same figure for clarification. The final diagram is in form of molecular electrostatic potential (MEP) maps. MEP maps of studied compounds are calculated and presented in Figure 4.

According to Figure 3, electrons are mainly localized on the benzene rings and heteroatoms. There are different colours on these maps. It can be easily understood that the benzene ring which has coordinated $\mathrm{t}-\mathrm{Bu}$ groups is more active than the other because its $\pi$ electrons are more active due to the red region. However, it cannot be claimed that the other benzene ring is inactive. Additionally, there is red color in the environment of heteroatoms of the studied compounds. In summary, it can be stated that electrons are mainly localized on the benzene ring and in the environment of heteroatoms. These sites are the most appropriate sites for the nucleophilic attack, while blue regions are appropriate for the electrophilic attack. 


$$
-4 \times 10^{-2}
$$

$+4 \times 10^{-2}$

B1
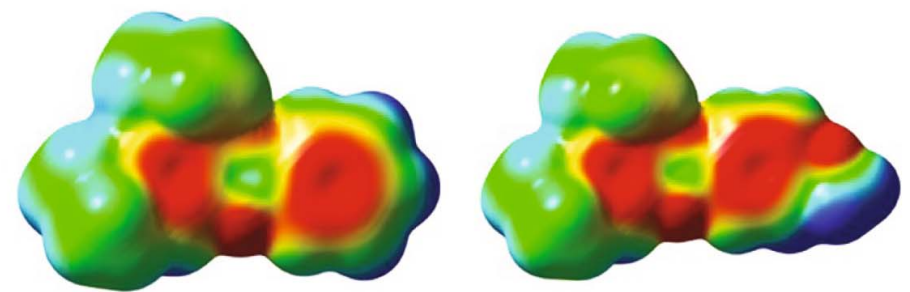

B3
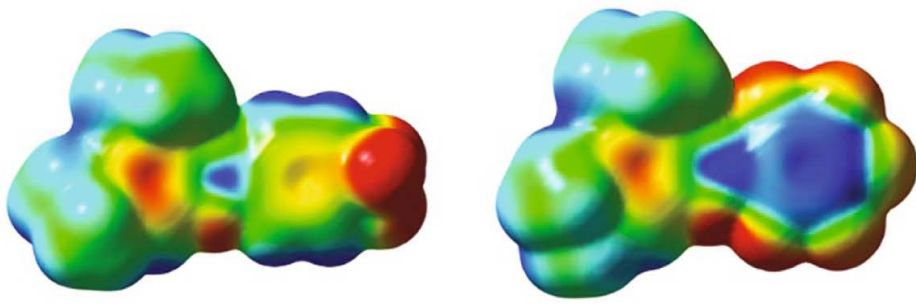

B4
B5
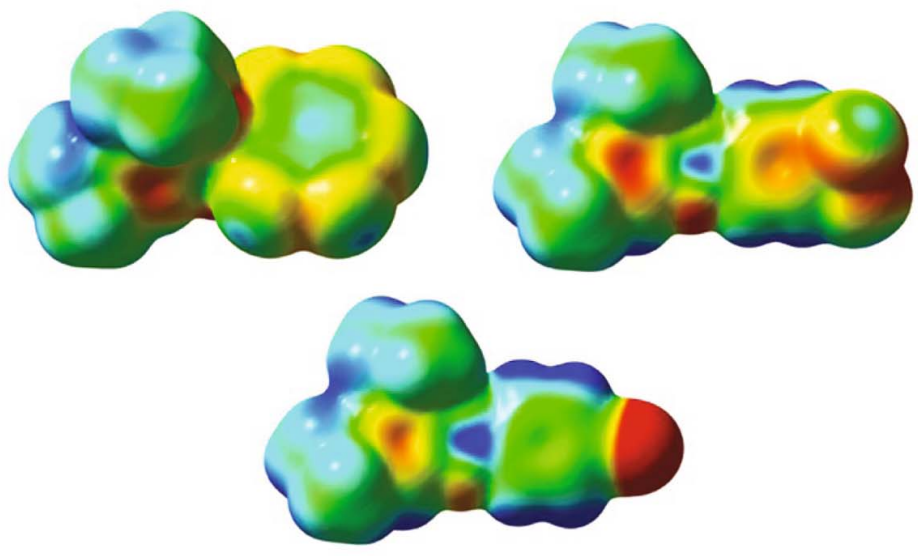

B7

Fig. 4. The calculated MEP maps of studied compounds (B1-B7). face area (LE-SA), energy of model ( $\left.\mathrm{E}_{\text {Model }}\right)$, van der Walls energy $\left(\mathrm{E}_{\mathrm{vDW}}\right)$, coulomb energy $\left(\mathrm{E}_{\text {Coul }}\right)$, and total interaction energy $\left(\mathrm{E}_{\mathrm{Int}}\right)$ are given in Table 2.

According to Table 2, the whole compounds are not found to be effective against SARS-CoV-2. Three docking poses are tried for each drug candidate. For RdRp, B1 is found to be effective. However, the docking score is so small, and the energy model has a positive value. Therefore, it can be easily said that studied compounds are not active against RdRp. As for the other proteins, two different compounds are found to be active. Although the docking score of B1 is higher than that of B7 in $6 \mathrm{LZG}$, the efficacy of $\mathrm{B} 7$ is higher than that of $\mathrm{B} 1$. The interaction energy and energy model are higher than those of B1. Also, one pose is found for B1 while two poses are found for B7. The energy values of the two poses of B7 are very similar to each other. Finally, B7 is a better drug candidate for the spike glycoprotein.

In the main protease, B2 and B5 are found to be effective against COVID-19. The docking score of $\mathrm{B} 2$ is higher than that of B5. In B2, the second pose is better than the first one. The total interaction energy, model energy, and van der Walls energy are higher. Docking structures between B7(1) and $6 \mathrm{LZG}$ as well as B2(2) and 6WTT are presented in Figure 5. The interaction scheme is presented together with the latter figure. MM/GBSA calculations are done for selected interactions. The calculation results for MM/GBSA are given in Table 3.

\section{Inhibitory efficiency against SARS-CoV-2}

The SARS-CoV-2 virus has been seen in Wuhan/China and spread all over the world (21-23). This virus has completely affected people's daily life, social life and relationships. Many clinical treatments have been used, while the treatment modes vary from country to country. Especially, it is reported that BCCs can be useful in the treatment of COVID-19. Three vital proteins, namely RdRp, spike glycoprotein and main protease, are selected as 6YYT, 6LZG, and 6WTT for in silico analyses. Molecular docking calculations are performed between drug candidates and RBD of target proteins. It is found that only five compounds are found to be active. Effective compound against $6 \mathrm{YYT}$ is $\mathrm{B} 1$; $\mathrm{B} 1$ and $\mathrm{B} 7$ are effective against $6 \mathrm{LZG}$; B2 and B5 are found to be active against $6 \mathrm{WTT}$. Additionally, B1 has only one docking pose against both 6 YYT and 6LZG; B5 has only one docking pose against 6WTT; B2 and $\mathrm{B} 7$ have two poses against $6 \mathrm{WTT}$ and $6 \mathrm{LZG}$, respectively. The docking score (DS), ligand efficiency (LE), ligand efficiency sur-

\section{MM/PBSA molecular dynamic calculation}

Molecular docking calculations for nanosecond-level binding calculations between molecules and proteins have some drawbacks. In molecular docking calculations, although inhibitors are very flexible, proteins are not flexible at all. The functions of molecular mechanics are used in combination with PoissonBoltzmann surface area (MM-PSBA) calculations to examine the interaction between molecules and proteins in greater detail. With these calculations, flexibility is given to both proteins and inhibitors. In these calculations, the protein as well as inhibitor are surrounded by solvent molecules. Protein (6LZG) and its complex structure at each 25-ns interval in range of $0-100 \mathrm{~ns}$ are presented in Figures 6 and 7, respectively.

The total binding energy between the drug candidate and target proteins are calculated for each of 5-ns intervals. The energy values are given in Table 3. Energy change graphs in the range of $0-100$ ns are plotted and represented in Figure 8. 


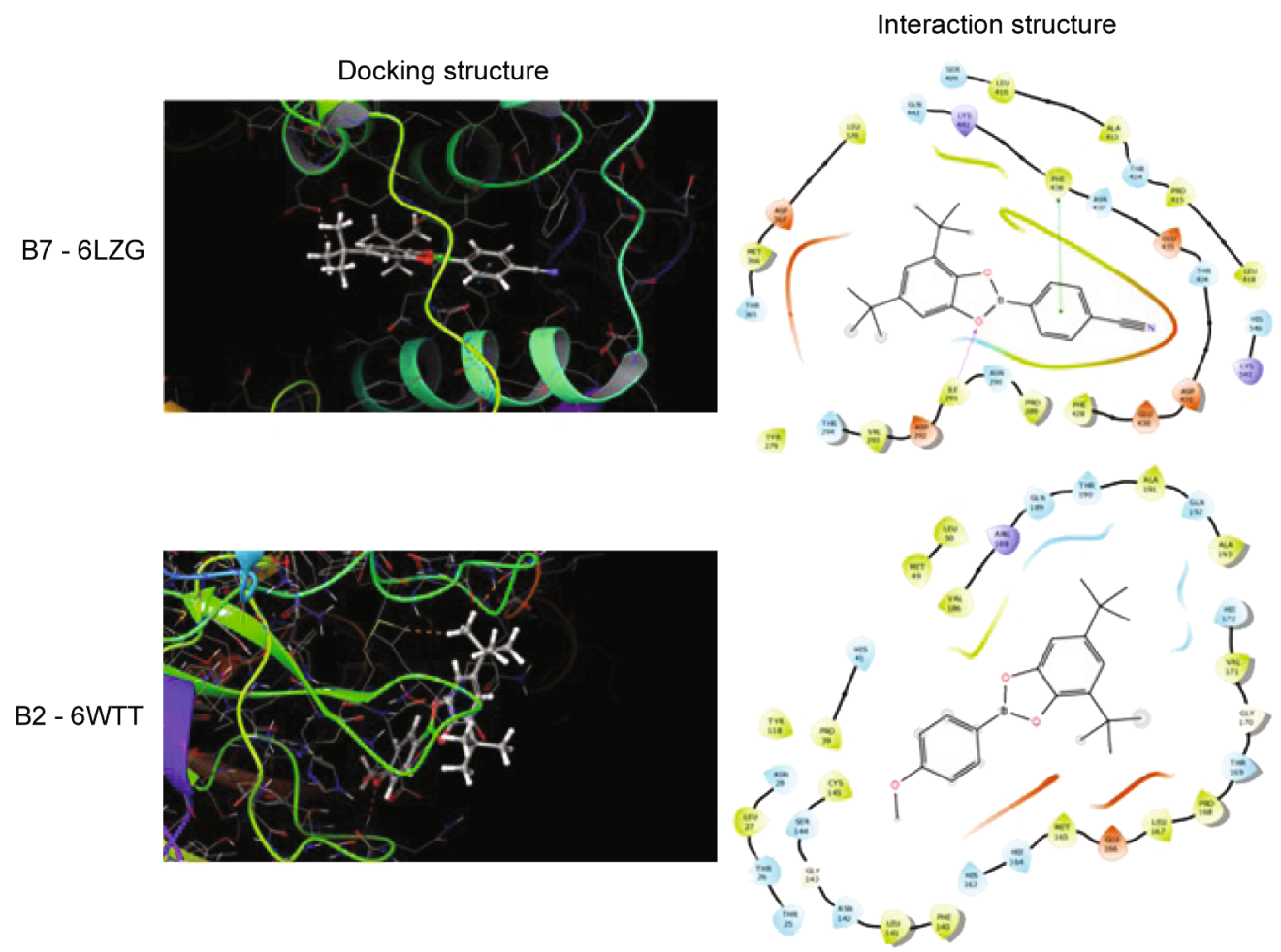

Fig. 5. The docking and interaction structures.

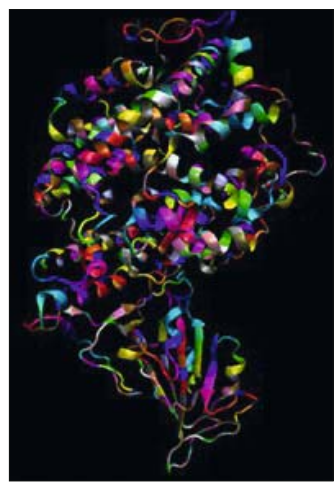

0 ns

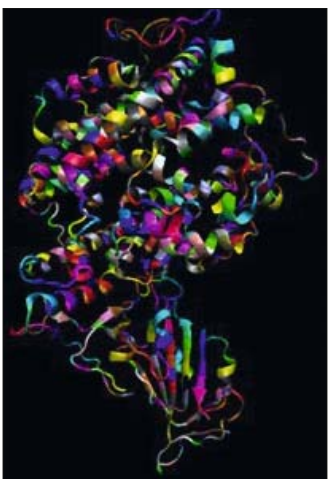

$25 \mathrm{~ns}$

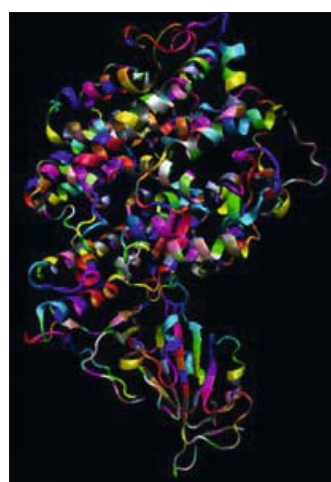

$50 \mathrm{~ns}$

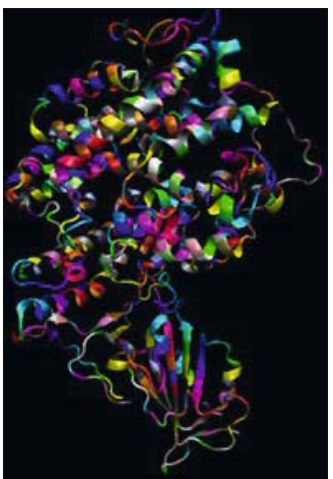

$75 \mathrm{~ns}$

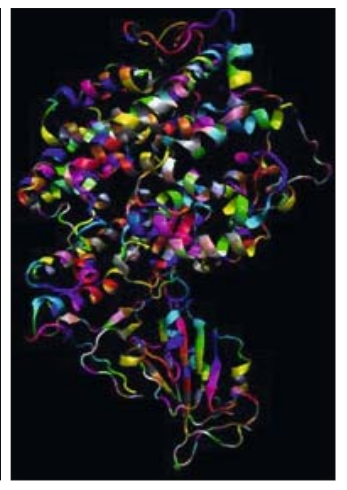

$100 \mathrm{~ns}$

Fig. 6. The protein structures at each $25-\mathrm{ns}$ interval in range of $0-100 \mathrm{~ns}$.

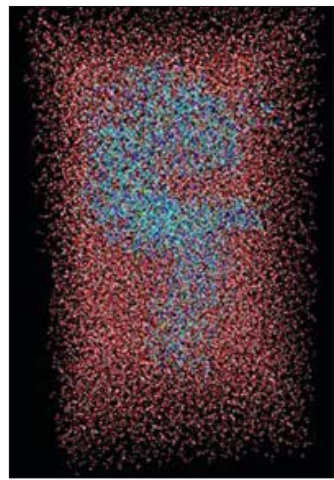

$0 \mathrm{~ns}$

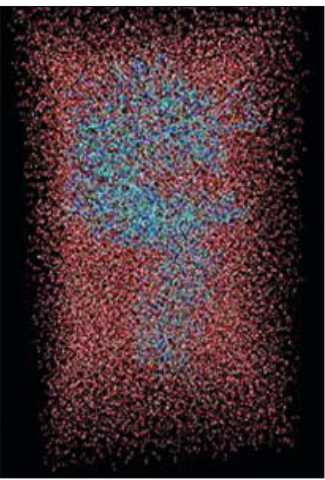

$25 \mathrm{~ns}$

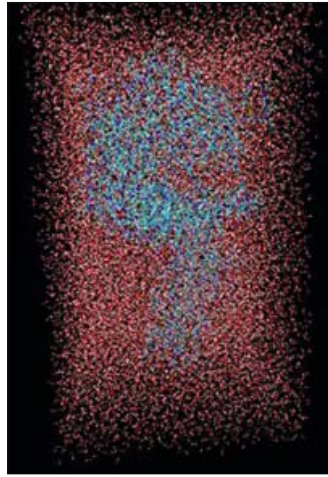

$50 \mathrm{~ns}$

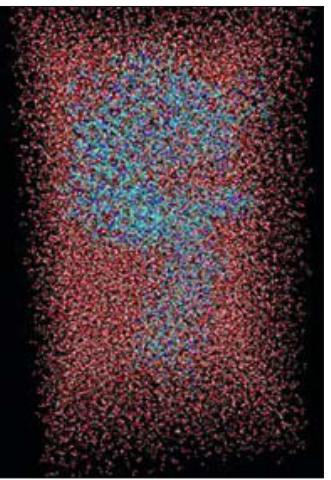

$75 \mathrm{~ns}$

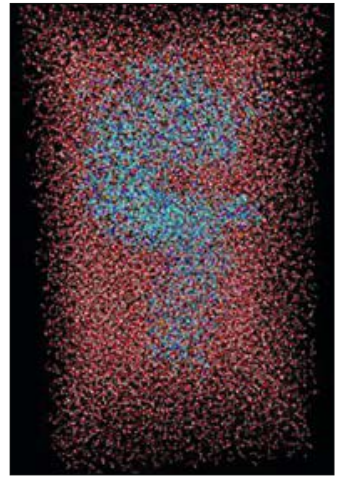

$100 \mathrm{~ns}$

Fig. 7. The complex structures surrounded by water molecules at each 25-ns interval in range of 0 - 100 . 
Tab. 3. The Gibbs binding energy ( $\mathrm{kcal} / \mathrm{mol}$ ) for drug candidates and target proteins at each 5-ns interval.

\begin{tabular}{rcc}
\hline Time & B7 -6 LZG & B2 $-6 W T T$ \\
\hline 0 & -1866.14 & -34064.90 \\
5 & -654.55 & -26683.79 \\
10 & -898.82 & -25875.00 \\
15 & -517.37 & -25269.67 \\
20 & -836.91 & -26529.63 \\
25 & -137.17 & -25518.17 \\
30 & -968.17 & -26465.48 \\
35 & -176.95 & -26215.36 \\
40 & -891.98 & -25397.22 \\
45 & -978.23 & -25355.00 \\
50 & -988.60 & -25597.00 \\
55 & -328.01 & -26429.73 \\
60 & -485.09 & -25598.08 \\
65 & -369.46 & -25434.89 \\
70 & -1120.31 & -25694.89 \\
75 & -463.90 & -26171.75 \\
80 & -555.51 & -25136.59 \\
85 & -723.05 & -26469.78 \\
90 & -980.15 & -25640.22 \\
95 & -895.42 & -25904.45 \\
100 & -784.33 & -25796.94 \\
\hline
\end{tabular}

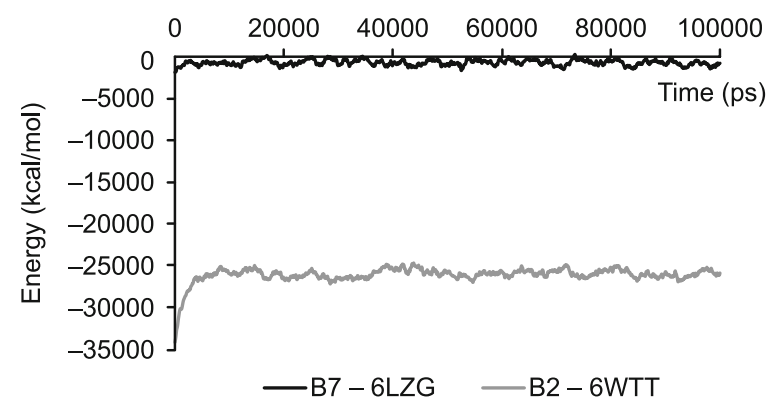

Fig. 8. The Gibbs binding energy in the range of $0-100 \mathrm{~ns}$.

According to Table 3 and Figure 7, it can be said that the studied BCCs are effective against SARS-CoV-2. Boron compounds have been reported as being effective against spike glycoproteins of SARS-CoV-2. However, because the Gibbs energy is so small, its effect on spike protein is judged not to be as good as reported. On the other hand, BCCs can be good alternative agents against the main protease of SARS-CoV-2 because the Gibbs binding energy in B2-6WTT complex is higher than that of the B7-6LZG complex. As a result, BCCs can be a drug candidate for the main protease of SARS-CoV-2.

\section{Conclusions}

Dioxaborole compounds are investigated by quantum chemical calculations. Structural and spectral characterizations are done in detail at the M06-2X/6-31+G(d,p) level in water. Their antiviral effects are examined by in silico techniques. SARS-CoV-2 virus selected as the target and its three proteins, which are main protease, spike glycoproteins and RNA-dependent RNA polymerase, are determined as 6WTT, 6LZG and 6YYT, respectively. Molecular docking analyses between studied compounds and the receptorbinding domain of target proteins are performed. It is determined that the studied dioxaborole compounds are effective against the main protease and spike glycoproteins. Then, molecular dynamic calculations, namely MM/PSBA are performed. It is determined that BCCs can be more effective against the main protease of SARS-CoV-2 than against its spike glycoprotein.

\section{Highlights}

- Boron-containing compounds were investigated as an anti-viral agent against SARS-CoV-2.

- Molecular dockings were performed between BCCs and target proteins.

- Main protease, RdRp and spike glycoproteins were selected as target proteins for SARS-CoV-2.

- Protein and drug candidates are accepted as flexible in MD calculations (MM/PSBA).

- Gibbs binding energy levels in the range of $0-100$ ns were calculated.

\section{References}

1. Braye EH, Hübel W, Caplier I. New Unsaturated Heterocyclic Systems. I. J Am Chem Soc 1961; 83 (21): 4406-4413.

2. Varvounis G Boroles. Comprehensive Heterocyclic Chemistry III 3 $2008 ; 1225-1241$.

3. Braunschweig H, Fernandez I, Frenklin G et al. Angew Chem Int Ed. 2008; 47; 951-1954.

4. Farfan-Garcia ED, Castillo-Mendieta NT, Cipres-Flores FJ et al. Current data regarding the structure-toxicity relationship of boron-containing compounds. Toxicology 2016; 258: 115-125.

5. Bentley J.N, Caputo CB, Substituent effects on the Lewis acidity of 4,6-di-tert-butylchatechol boronate esters, Tetrahedron 2019; 75 : $31-35$.

6. Orak F, Gundes A, Yalcinkaya KT et al. Could boron be used as coronavirus inactivation agent? Bratisl Med J 2020; 121 (9): 686.

7. Wang Q, Zhang Y, Wu L et al. Structural and Functional Basis of SARS-CoV-2 Entry by Using Human ACE2, Cell 2020; 181: 894-904.e9.

8. Hillen HS, Kokic G, Farnung L et al. Structure of replicating SARSCoV-2 polymerase. Nature 2020; 584: 154-156.

9. Ma C, Sacco MD, Hurst B et al. Boceprevir, GC-376, and calpain inhibitors II, XII inhibit SARS-CoV-2 viral replication by targeting the viral main protease, Biorxiv 2020. DOI: 10.1101/2020.04.20.051581.

10. Dennington II RD, Keith TA, Millam JM. GaussView 5.0, Wallingford, CT, 2009.

11. Frisch MJ, Trucks GW, Schlegel HB et al. Gaussian09 AS64LG09RevD.01, Gaussian, Inc, Wallingford CT, 2009.

12. Schrödinger Release 2019-4: LigPrep, Schrödinger, LLC, New York, NY, 2019.

13. Schrödinger Release 2019-4: Maestro, Schrödinger, LLC, New York, NY, 2019 
14. Friesner RA, Murphy RB, Repasky MP et al. Extra precision glide: Docking and scoring incorporating a model of hydrophobic enclosure for protein-ligand complexes. J Med Chem 2006; 49 (21): 6177-6196.

15. Friesner RA, Banks JL, Murphy RB et al. Glide: a new approach for rapid, accurate docking and scoring. 1. Method and assessment of docking accuracy. J Med Chem 2004; 47 (7): 1739-1749.

16. Humphrey W, Dalke A, Schulten K. VMD: visual molecular dynamics. J Mol Graph 1996; 14(1): 33-38.

17. Nelson MT, Humphrey W, Gursoy A et al. NAMD: a parallel, object-oriented molecular dynamics program, The International Journal of Supercomputer Applications and High Performance Computing 1996; 10 (4): 251-268.

18. Üngördü A, Sayin K. Quantum chemical calculations on sparfloxacin and boron complexes. Chem Phys Lett 2019; 733: 136677.

19. Senaratne NK, Mwania TM, Moore CE et al. Ni complexes of N2S ligands with amine/imine and amine/amide donors with relevance to the active site of $\mathrm{Ni}$ superoxide dismutase. Inorganica Chim Acta, 2018; 476: $27-37$.
20. Tüzün B, Sayin K. Investigations over optical properties of boron complexes of benzothiazolines. Spectrochimica Acta Part A: Mol Biomol Spectroscopy, 2019; 208: 48-56.

21. Aktaş A, Tuzun B, Taskin Kafa AH et al. How do arbidol and its analogs inhibit the SARS-CoV-2? Bratisl Medl J 2020; 121 (10): $705-711$.

22. Aktaş A, Tuzun B, Aslan R et al. New anti-viral drugs for the treatment of COVID-19 instead of favipiravir, Journal of Biomolecular Structure and Dynamics 2020. DOI: 10.1080/07391102.2020.1806112.

23. Gedikli MA, Tüzün B, Aktaş A et al. do clarithromycin, azithromycin and their analogues effective in the treatment of COVID-19? Bratisl Med J 2021: 122.

Received October 28, 2020. Accepted November 16, 2020. 